\title{
Research on the Present Situation of Advertising Teaching in Applied Colleges
}

\author{
Zhi $\mathrm{Li}^{1, \mathrm{a}}$, Yuemeng $\mathrm{Ge}^{2, \mathrm{~b} \text {, * }}$ \\ ${ }^{1}$ Zhejiang University Ningbo Institute of Technology, Ningbo315000, China \\ ${ }^{2}$ Zhejiang Fashion Institute of Technology, Ningbo315000, China \\ alizhi@nit.zju.edu.cn, b, ${ }^{\star}$ gyuemeng@126.com
}

\begin{abstract}
In the past 30 years, the majors of Chinese higher education institutions have become more and more sophisticated. Advertising has become a second-level discipline under the discipline of journalism and communication through the integration of academics and practice. At present, according to the professional attributes of colleges and universities, there are different logical division standards for advertising majors. From the content point of view, it can be divided into four categories: advertising practice, advertising theory, advertising history and advertising criticism. However, in the actual teaching process, there is still a great disagreement between the advertising academia and the advertising industry on advertising, which has always threatened a potential and necessary tension. In general, the common recognition of advertising disciplines by all sectors of society is an applied discipline. Therefore, how to train students to improve their innovative ability in practice and serve the society in advertising teaching requires advertising teachers to break the routine in advertising teaching, carry out role transformation, strive to connect advertising theory and explore the basis of education science in the new era with innovative practice.
\end{abstract}

Keywords: Applied Colleges; Advertising Teaching; Advertising Competition; Creative Practice.

\section{Introduction}

Advertising teaching itself has distinct characteristics of The Times, which is based on and synchronized with the information economy era. Advertising teaching, as a theoretical and practical explorer in the major of advertising, requires teachers to change their roles in many aspects to adapt to the development of global economy. At the same time, it emphasizes that advertising teachers are not only the exporter of knowledge, but also the guide of students' learning. In the process of changing the educational environment from closed to open, the relationship between one-way teaching output and students' passive acceptance should be changed. In reality, middle school students are no longer docile listeners in the age of traditional media, but they hate the classroom. To change this situation, teachers need to put forward reasonable learning objectives and planning methods with their teaching ability and experience, help students arrange learning materials appropriately, create a good learning atmosphere, and guide students into deeper knowledge research and higher stage of active learning. In addition, in the process of advertising teaching, teachers should be promoted from the replicator of book knowledge to the cultivation of students' creative ability, so as to teach students in accordance with their aptitude in a real sense, drive students to find the way to adapt to the personality development of advertising characteristics, and promote the comprehensive development of students' individuality.

\section{The Present Situation of Advertising Teaching in Applied Colleges}

First of all, the teaching curriculum emphasizes theory and practice lightly. Due to the limitations of teaching conditions, many applied colleges do not have enough training bases, computer rooms, etc. when conducting advertising teaching. Practice teaching cannot be carried out smoothly. Many teaching links are stuck in the entry stage, and students' practical ability is generally low. At the same time, teaching time is also very limited, some teachers also despise practical teaching, and believe that the transfer of theoretical knowledge is more important. For this reason, in the case of insufficient investment in school practice, the teaching emphasizes theory and practice lightly. 
Secondly, the captive teaching makes students' innovative thinking not improved. Advertising creativity is carried out on the basis of strong innovative thinking, and improving students' creative thinking ability is also one of the teaching goals that college advertising should pay attention to. However, many colleges and universities are influenced by traditional teaching concepts. It is believed that students should study in schools and adopt captive teaching to restrict students from contacting the society. On the basis of insufficient practical experience, students' creative thinking is severely limited, and their ability to innovate is relatively limited. Lower.

Thirdly, there are many advertising teaching modes and few application types. With the continuous reform of the education system, the cultivation of applied talents has been paid attention to, but in most colleges and universities, due to the deep-rooted concept of exam-oriented education, the application-based teaching model has not yet been truly practiced. Almost all colleges and universities evaluate students according to their test scores, and even as the only criterion for assessing students, causing students to misunderstand. Passing the exam becomes the main purpose of learning. In the early stage of the exam, it is mainly based on rote memorization to enhance their knowledge. Mastering, resulting in poor knowledge and memory after the test, lack of practical ability.

Finally, the curriculum of the advertising major is unreasonable. The advancement of the times puts higher demands on advertising talents. The traditional advertising courses are no longer applicable. Further, art design and business school courses such as market research, brand positioning, consumer psychology, new media advertising design, and advertising are needed. Courses such as photography improve the advertising chain. However, many colleges and universities do not meet the above conditions in the curriculum, the curriculum knowledge is relatively old, the course content can not meet the market demand, resulting in the cultivation of advertising talents are not recognized by the society.

\section{The Innovative Practice Path of Advertising Teaching Mode in Applied Colleges}

\subsection{The Cultivation of Advertising Creative Thinking}

Advertising creativity as a compulsory core course in advertising, teachers need to have strong professional skills. The reason is that creativity needs skilled industry skills, and advertisers can visually show the reputation and popularity of the product according to the full and detailed market research results, showing the psychology of product owners and consumers, advertising strategy and other factors. Advertising creativity is the beginning of product planning, which can determine whether the product successfully goes to the market. A good idea can become a classic advertisement, but also can bring unexpected benefits to customers.

First of all, in the creative teaching of advertising, students should be cultivated creative thinking and continuously improve their creative ability. To enhance students' creative ability, students must master the training skills of acquiring creative thinking, learn the creative thinking of classic advertising cases, and master the knowledge of more disciplines. The accumulation of rich knowledge and experience is the source of creativity, the premise of excellent advertising works, and actively cultivate students' professional personality development in advertising education and teaching, and guide students to enhance their comprehensive advertising quality.

Secondly, in the creative teaching of advertising, students should be trained in the ability to observe fashion culture, and guide students to pay attention to social culture and cultivate a keen sense of culture. Advertising creativity is closely related to fashion culture because advertising itself is a popular pop culture, and creativity must be acceptable to the audience and quickly resonate. However, the most difficult course in the entire advertising teaching process is also "Advertising Creativity." The cultivation of creative ability, in terms of students, requires love and attention to life. The inspiration for creativity is not something that is ethereal, but something that comes from life. The improvement of creative ability requires continuous learning and accumulation, so that creative inspiration can be emanating instantly. 


\subsection{Participate in Training with the Help of Advertising Contests}

As an artistic and highly applied subject, advertising theory is not the best teaching method, especially the students' pursuit of knowledge and interest in learning. Teachers can conduct various commercial or public welfare competitions through social institutions, education departments and other subjects to lead students to participate actively. By participating in the "advancement of teaching by teaching" and "employee training" advertising teaching and training methods, students' ability to create thinking and improve students' ability to enter social practice in advance. At the same time, by participating in international and domestic advertising competitions, it is conducive to fostering students' sense of honor and enhancing students' self-confidence. It is also possible to further develop students' sense of competition and tap the creative potential of students. However, in the actual teaching of advertising in colleges and universities, teachers do not form a good mechanism to lead students to participate in various advertising competitions, and there is no corresponding policy support. Although there are corresponding clauses explaining the importance of advertising competitions, they all stay on paper, which leads to the enthusiasm of teachers. In fact, students can participate in the evaluation of their professional courses in the award-winning works, and can also edit the excellent works into a book as an extended learning material for future education and teaching.

\subsection{Strengthen the Practice of Advertising Planning}

In the advertising major, the core curriculum is "Advertising Planning". The ability of students to plan and practice training determines the degree of mastery of knowledge. In the practice of the advertising industry, advertising planning belongs to a thinking activity with comprehensive ability and strong creative requirements. Students need to do various preparations during the training process. Through careful market research and system analysis, the marketing strategy and activity process are effectively and reasonably arranged, and the lower advertising costs are used to obtain larger promotion effects as much as possible. The advertising planning work includes determining the target of advertising, advertising market research, and advertising brand. Targeting, campaign strategy and execution, advertising media strategy, advertising budgeting, ad performance estimates, and more. At the same time, it is necessary to train students to master the theoretical knowledge related to advertising, including the basic ability of advertising design, the ability to write advertising copy, the organization ability of advertising activities and the ability to produce and distribute. The message is to let students understand the comprehensive comprehensive needs of advertising planning. Ability and consciously learn consciously. After the end of the classroom teaching theory knowledge, students can be recommended to the advertising company internship, or practice the proposition, organize students to conduct a detailed advertising market survey, write an advertising plan, invite advertising professionals to comment and guide, through the scene Teaching interactions to develop students' practical work ability.

\subsection{Adding Advertising Experiential Learning Courses}

In the process of advertising teaching, it is necessary to adopt flexible experiential teaching method according to the actual situation of students. First of all, it is situational experience. Through setting teaching situational mode, students are immersed in it. For example, the creation of a set of advertising shooting scene, let students experience each link, the teacher then put forward the situation facing different links, let students find out the solution to the problem in the situation. Secondly, it is the role experience to cultivate students' empathy ability and enrich their experience. It is also helpful for students to understand the communication, understanding and cooperation of different social roles from different knowledge perspectives. For example, in an advertisement video, students play the leading role, supporting role and the person in charge of the venue, so that students can think about problems from different roles. Thirdly, it is the operation experience to enhance students' interest in learning. Through the field practice, let the students get the sense of experience in the advertising operation activities, stimulate the interest of students, enable students to apply what they have learned, and understand the truth contained in the operation experience teaching. From the experience of advertising teaching, it can be seen that most courses of advertising require students to 
have strong practical ability, which should be the focus of training students' operational ability. Students should constantly strengthen their active practice in advertising graphics, text color, new media application and other aspects, explore and experience teaching, and improve their innovative ability. In addition, in advertising classroom teaching, taking classic successful advertising cases as models to analyze to students, is a kind of exploration and discovery learning, is a kind of knowledge construction learning, help to eliminate students' thinking blind spots, avoid mistakes in future advertising design, can quickly improve students' comprehensive ability.

\section{Summary}

After more than 30 years of development in China's advertising industry, the development of modern enterprises has also shifted from product marketing to brand marketing, which has risen to the advanced stage of brand communication and network marketing. In 1983, Xiamen University founded China's first advertising major. Advertising education has been produced and developed in China for more than 30 years as a new education field. However, the current situation is that the development of China's advertising education is far behind the development of the advertising industry. As a breeder of the advertising industry, colleges and universities should understand the cultivation of advertising application talents from a higher perspective and cultivate students' creativity through multiple channels. With the support of the relevant government departments in the advertising industry policy, it is necessary to fully mobilize the enthusiasm of colleges and universities, advertising companies and enterprises to make full use of their strengths. However, the purpose of advertising education is not only the knowledge transfer and the mastery of basic skills, but more importantly, it is to guide students to improve their new concepts of adapting to modern development, and to comprehensively apply their knowledge, and truly have the conditions to become a professional in the advertising industry. At the same time, reform the teaching mode, strengthen the construction of advertising professional teachers, to meet the actual needs of the society as the starting point to carry out teaching, so that students quickly enter the work after graduation, become a new force to promote social and economic progress.

\section{References}

[1]. Yueyu Yan. The Application and Innovation of Advertising Teaching Mode in Colleges and Universities[J]. Journal of Jinlin Business and Technology College. Vol.32, No.1, Feb.2016.

[2]. Chenliang Daia. Some theoretical problems in advertising teaching[J]. Journal of Donghua University (Social Sciences), Vol.2, No.1, Mar.2002.

[3]. Feng Jin. On Advertising Teaching and Practical Application[J]. Jilin Normal University Journal: Humanities \& Social Science, No.6, Nov.2013.

[4]. Mingyang Yu, Xianhong Chen. Advertising planning[M]. Shanghai: Fudan University press. 2009.

[5]. Liqi Jin. Advertising Science - Theoretical Practice Case Training[M]. Beijing: Higher Education Press, 2010.

[6]. Binlin Lou. Advertising theory and practice[M]. Beijing: Higher Education Press,2010.

[7]. Zhiyong Zhu. Innovation of the Training Mode of Advertising Professionals in Local Comprehensive Universities under the Vision of New Media[J]. Heilongjiang Higher Education Research. 2015, (5).

[8]. Taoliang Liu. Construction of Practice Teaching System for Advertising Majors in Local Universities__-Taking Qujing Teachers College in Yunnan as an Example[J]. Advertising Panorama, 2009, (6). 